\title{
Basilar invagination, Chiari malformation, syringomyelia: A review
}

\author{
Atul Goel
}

Professor and Head, Department of Neurosurgery, K.E.M. Hospital and Seth G.S. Medical College, Parel, Mumbai 400 012, India

\author{
Address for correspondence: \\ Dr. Atul Goel, \\ Department of Neurosurgery, \\ K.E.M. Hospital and Seth G.S. \\ Medical College, Parel, \\ Mumbai 400 012, India. \\ E-mail: atulgoel62@hotmail.com
}

DOI : $10.4103 / 0028-3886.53260$

\begin{abstract}
Institute and personal experience (over 25 years) of basilar invagination was reviewed. The database of the department included 3300 patients with craniovertebral junction pathology from the year 1951 till date. Patients with basilar invagination were categorized into two groups based on the presence (Group A) or absence (Group B) of clinical and radiological evidence of instability of the craniovertebral junction. Standard radiological parameters described by Chamberlain were used to assess the instability of the craniovertebral junction. The pathogenesis and clinical features in patients with Group A basilar invagination appeared to be related to mechanical instability, whereas it appeared to be secondary to embryonic dysgenesis in patients with Group B basilar invagination. Treatment by facetal distraction and direct lateral mass fixation can result in restoration of craniovertebral and cervical alignment in patients with Group A basilar invagination. Such a treatment can circumvent the need for transoral or posterior fossa decompression surgery. Foramen magnum bone decompression appears to be a rational surgical treatment for patients having Group B basilar invagination. The division of patients with basilar invagination on the basis of presence or absence of instability provides insight into the pathogenesis of the anomaly and a basis for rational surgical treatment.
\end{abstract}

Key words: Atlantoaxial, basilar invagination, Chiari malformation, craniovertebral, syringomyelia

\section{Introduction}

The subject of craniovertebral junction anomalies is under discussion and evaluation for over a century. A number of classical reviews have attempted to clarify a variety of complex associated issues. Despite the volumes of publications on the subject, it appears that the last word has not yet been said. Craniovertebral anomalies are more frequently found in the Indian subcontinent than anywhere else in the world. Even in India, these anomalies are more frequently documented form Uttar Pradesh, Bihar, Rajasthan and parts of Gujarat. The reasons for this geographical clustering are speculative. Over the years, there have been a relatively large number of significant and authoritative publications from India on this subject.

The surgical management of congenital craniovertebral anomalies is complex due to the relative difficulty in accessing the region, critical relationships of neurovascular structures and the intricate biomechanical issues involved. Basilar invagination forms a prominent component of the craniovertebral anomalies. Chiari malformation and syringomyelia are common associates of basilar invagination and are the soft tissue components of the dysgenesis. Plain radiological and tomographic parameters have been principally used to diagnose basilar invagination for many years. There has been a renewed interest in the normal anatomy and pathologic lesions of the craniovertebral junction with the development of imaging by high-resolution computer tomography (CT) scan and magnetic resonance imaging (MRI). Improved imaging has provided an opportunity to clearly observe the bony abnormality and the distorted neural and vascular relationships. Dynamic MRI and CT scan have helped in the evaluation of the pathology of basilar invagination, in the assessment of the biomechanics of the joints and in the formulation of a rational surgical 
strategy. Despite the clarity of imaging, controversy regarding the management of basilar invagination continues. Even the natural history has not been clearly elucidated in the literature. The surgical indications for a given approach together with the timing of the surgical stages are still under discussion.

\section{Pathogenesis}

Several theories have been suggested to elucidate the probable cause and origin of basilar invagination and they include mechanical or embryological dysgenesis, genetic abnormalities, and viral infections. ${ }^{[1-5]}$ Most anatomists, for over a century, have thought that deformation had a mechanical cause and therefore applied the name: 'impressio baseos cranii' ${ }^{[6]}$ or basilar impression. ${ }^{[7]}$ Grawitz $^{[8]}$ believed that basilar invagination was often a result of under- or maldevelopment of the craniovertebral transition region. A range of malformations is frequently associated with anomalies of the atlas and axis, some of which may be quite atypical, and with fissures or defects and bone projections from the spinal column in the craniovertebral transition zone. The latter anomalies were grouped together by von Torklus and Gehle ${ }^{[7]}$ as suboccipital dysplasias.

We had speculated that basilar invagination is secondary to abnormally inclined alignment of the facets of the atlas and axis. ${ }^{[9]}$ The progressive slippage of the atlas over the axis secondary to this malalignment, a process similar to spondylolisthesis in the lumbosacral spine, results in invagination of the odontoid process into the craniocervical cord. ${ }^{[9,10]}$ Some authors have alluded to the progressive nature of the anomaly of basilar invagination. ${ }^{[10]}$

Short neck, low hairline, web-shaped neck muscles, torticollis, reduction in the range of neck movements, and several such physical variations have been described as hallmarks of basilar invagination for over a century. A number of bone fusion deformities and platybasia have also been recorded. Neck pain, muscle spasms, and restriction of neck movements are frequently noted, suggesting instability of the region.

\section{Classification into Group I and II}

In the year 1997, we presented a classification system for basilar invagination that divided it into two discrete categories. This classification helped in clarifying the understanding of the pathology and pathogenesis of the anomaly, in the selection of the surgical treatment and in prediction of the outcome. ${ }^{[11]}$ The analysis was based on a study of 190 patients of basilar invagination surgically treated in our department during a ten-year period
(1988-97). Based on a single criterion of the absence or presence of Chiari malformation, the anomaly was classified into Group I and II respectively. Essentially, Group I included patients where there was invagination of the odontoid process into the foramen magnum and it indented into the brainstem. The tip of the odontoid process distanced itself from the anterior arch of the atlas or the inferior aspect of the clivus. The distancing of the odontoid process from the anterior arch suggested presence of instability of the region and atlantoaxial dislocation. The angle of the clivus and the posterior cranial fossa volume were essentially unaffected in these patiens. In Group II, on the other hand, the assembly of the odontoid process, anterior arch of the atlas and the clivus migrated superiorly in unison resulting in reduction of the posterior cranial fossa volume, which was the primary pathology in these patients. The Chiari malformation or herniation of the cerebellar tonsil was considered to be a result of reduction in the posterior cranial fossa volume. In the year 1997, we first defined the clinical implication of association of small posterior cranial fossa volume and Chiari malformation. ${ }^{[11]}$

\section{Classification into Group A and B}

In our recent study, we identified a subgroup of patients having basilar invagination where there was clear radiological evidence of instability of the region that was manifested by distancing of the odontoid process from the anterior arch of the atlas, and the radiological features matching those of Group I patients. Considering this current evaluation we have proposed a new classification for basilar invagination into two groups based on parameters that determine an alternative treatment strategy. ${ }^{[12]}$ In Group A basilar invagination there was a 'fixed' atlantoaxial dislocation and the tip of the odontoid process 'invaginated' into the foramen magnum and was above the Chamberlain line, ${ }^{[13]}$ McRae line of foramen magnum ${ }^{[14]}$ and Wackenheim's clival line. ${ }^{[15]}$ The definition of basilar invagination of prolapse of the cervical spine into the base of the skull, as suggested by von Torklus, ${ }^{[7]}$ was suitable for this group of patients [Figure 1]. Group B basilar invagination was where the odontoid process and clivus remained anatomically aligned despite the presence of basilar invagination and other associated anomalies. In this group, the tip of the odontoid process was above Chamberlain's line but below McRae's and Wackenheim's lines [Figure 2]. The radiological findings suggested that the odontoid process in Group A patients resulted in direct compression of the brainstem. Essentially, in Group A basilar invagination, there was an element of instability of the region that was manifested by the tip of the odontoid process distancing itself from the anterior arch of the atlas or the lower end of the clivus. In some Group A patients there was Chiari 


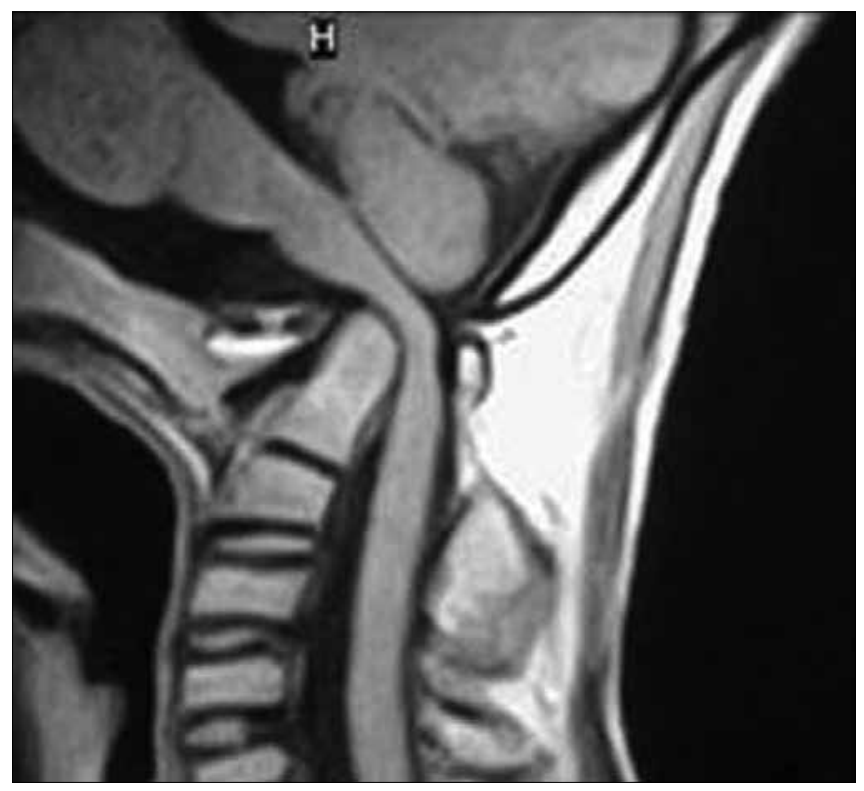

Figure 1a: T1-weighted MRI showing Group A basilar invagination. The odontoid process has invaginated into the foramen magnum

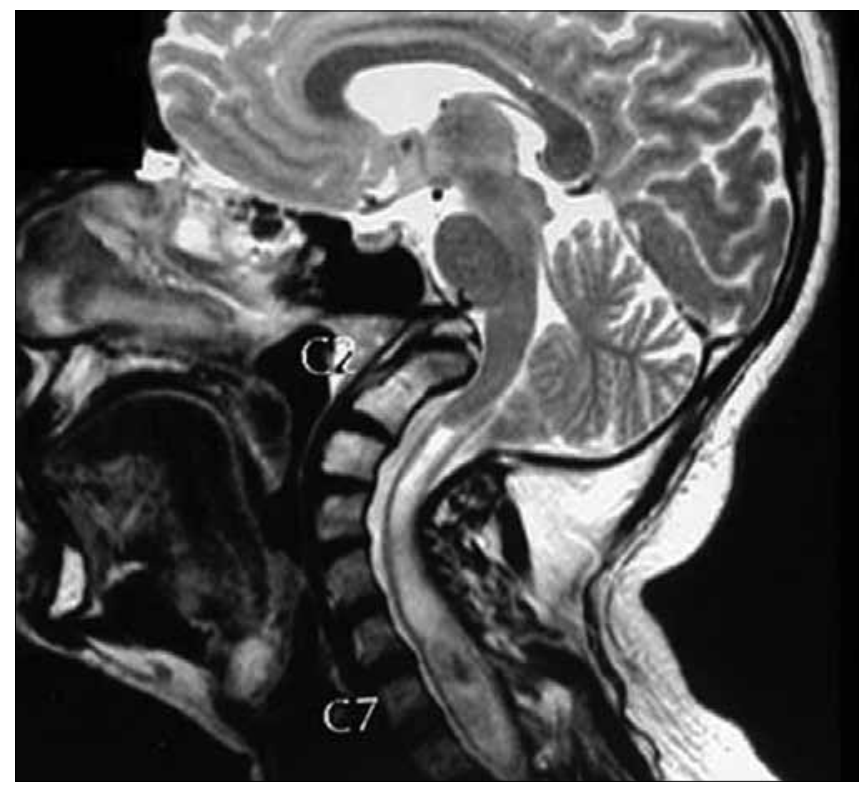

Figure 2a: T2-weighted MRI showing Group B basilar invagination. The odontoid process and the clivus relationship have been maintained.

The distance between the ponto-medullary junction and the tip of the odontoid process is markedly reduced. The brainstem girth is not remarkably reduced. Chiari malformation and syringomyelia can be seen

malformation, and this feature differentiates the present classification from the earlier classification. In this group, the atlantoaxial joints were 'active' and their orientation was oblique as shown in Figure 3, instead of the normally found horizontal orientation. We have found similarities of such a position of the C1-2 facets with spondylolisthesis seen in the subaxial spine. It appears to us that the atlantoaxial joint in such patients is in an abnormal position as a result of mechanical instability and progressive worsening of the dislocation is probably

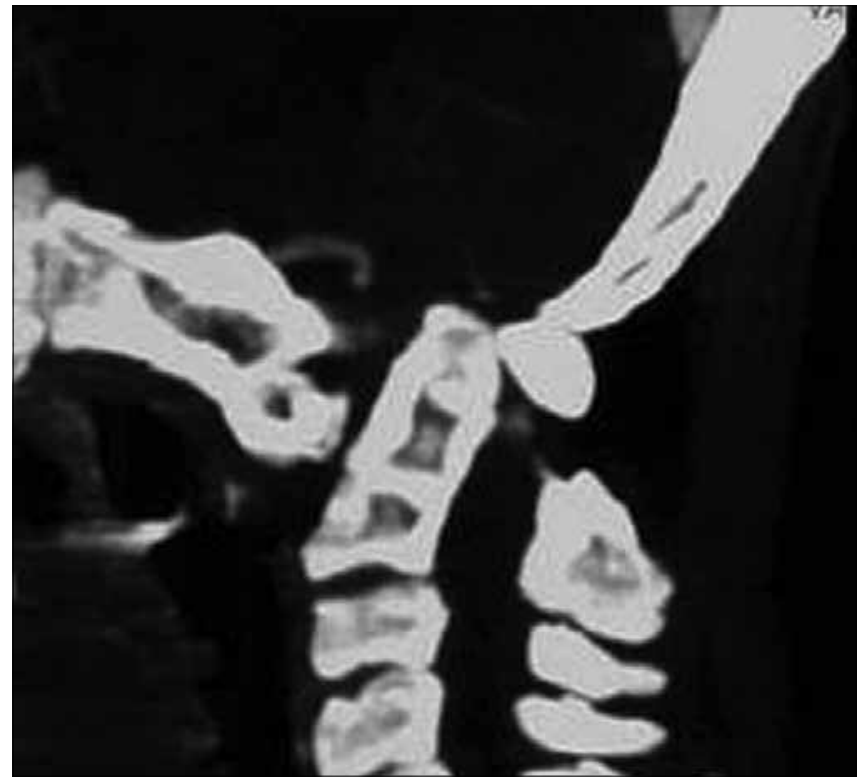

Figure 1b: CT scan showing Group A basilar invagination

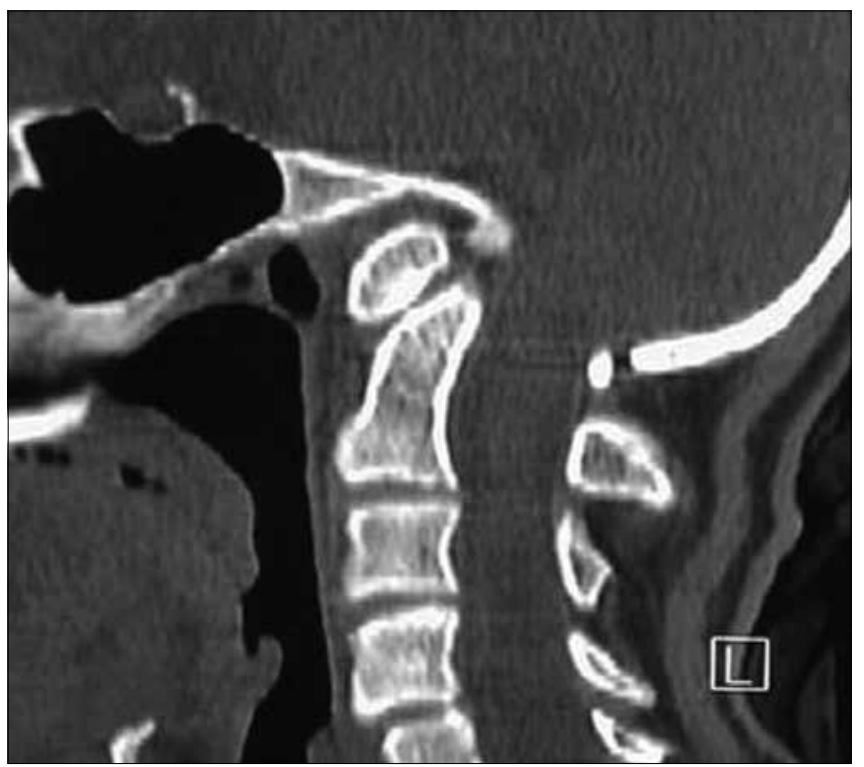

Figure 2b: CT scan showing Group B basilar invagination

secondary to increasing 'slippage' of the facets of atlas over the facets of axis. In Group B, the atlantoaxial joints were normal and were normally aligned. In some patients the joints were entirely fused. The pathogenesis of basilar invagination appears to be different in the two groups. Understanding these two types of basilar invagination is probably the most crucial factor in understanding the various involved management issues. Group A basilar invagination forms a larger subgroup of patients that are encountered in Indian subcontinent.

We had earlier speculated that patients of Group A 


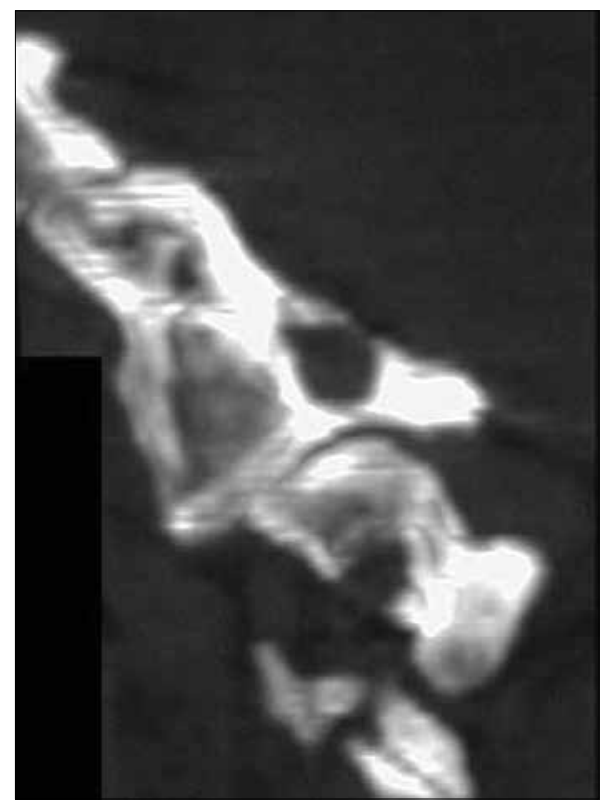

Figure 3: CT scan showing the listhesis of $\mathrm{C} 1$ facet over $\mathrm{C} 2$ facet. This listhesis of $\mathrm{C} 1$ over $\mathrm{C} 2$ is probably the cause of basilar invagination

basilar invagination and related bone and soft tissue dysgenesis may not be a congenital defect, but can be a result of mechanical 'incompetence' of the atlantoaxial joints. A number of bone and soft tissue anomalies are associated with basilar invagination. These include short neck, torticollis, platybasia, cervical vertebral body fusion (Klippel- Feil abnormality) including assimilation of atlas, spondylotic spinal changes and restriction of neck movements. A number of these abnormalities were seen to be reversible following decompression and stabilization of the region. ${ }^{[1]}$ Considering that several physical features associated with this group of basilar invagination are reversible, it appears that the pathogenesis in such patients may be more due to mechanical factors rather than congenital causes or embryological dysgenesis. The common teaching on the subject is that the short neck and torticollis are a result of embryological dysgenesis and effectively result in indentation of the odontoid process into the cervicomedullary cord. However, it appears that it is the cord compression due to indentation by the odontoid process that is the primary event and all the physical alterations and bony abnormalities, including the short neck and torticollis are secondary natural protective responses that aim to reduce the stretch of the cord over the indenting odontoid process. Pain, restriction of neck movements and hyperlordosis of the neck indicate the presence of instability of the craniovertebral junction.

\section{Diagnosis}

\section{Radiological criteria}

Chamberlain's line

Basilar invagination was diagnosed when the tip of the odontoid process was at least $2 \mathrm{~mm}$ above Chamberlain's line. ${ }^{[13]}$ Measurement of Chamberlain's line on lateral sagittal reconstruction pictures of CT scan and sagittal MRI was seen to be reliable and accurate. The analysis of basilar invagination into two groups on the basis of Chamberlain's line suggested that the basilar invagination is much more severe in Group B than in Group A.

Distance from odontoid tip to the pontomedullary junction The distance from the tip of the odontoid to the pontomedullary junction, as observed on MRI, was seen to be a useful index to define the reduction of the posterior cranial fossa bone size. ${ }^{[13]}$ The distance was markedly reduced in Group B patients while it was relatively large in Group A patients.

\section{Atlanto-dental or clivo-dental interval}

In Group A patients, it was seen that the odontoid process migrated superiorly and posteriorly into the foramen magnum and distanced itself from the anterior arch of the atlas and the inferior end of the clivus. As judged from the atlanto-dental or clivo-dental interval, there was an element of 'fixed' atlantoaxial dislocation in these patients. Actual mobility of the atlantoaxial joint on flexion and extension of the neck can be demonstrated only rarely. In our recent study, we identified patients in whom there was 'vertical mobile and reducible atlantoaxial dislocation', wherein there was basilar invagination when the neck was flexed, and the alignment was normal when the head was in extended position. Although such mobility is only rarely identified, it does indicate the need for dynamic flexion-extension studies to preoperatively assess the craniovertebral instability. ${ }^{[16]}$ In Group B the alignment of the odontoid process with the anterior arch of the atlas and with the inferior aspect of the clivus remains normal and there is no instability in these patients.

\section{Wackenheim's clival line}

The tip of the odontoid process was significantly superior to Wackenheim's clival line in Group A patients. In Group B patients, the relationship of the tip of the odontoid process and the lower end of the clivus and the atlanto-dental and clivo-dental interval remained relatively normal. In a majority of the patients, the tip of the odontoid process remained below Wackenheim's clival line ${ }^{[15]}$ and McRae's line of foramen magnum. ${ }^{[14]}$ The basilar invagination thus resulted from the rostral positioning of the plane of the foramen magnum in relation to the brainstem [Figure 2].

\section{Platybasia}

The association of platybasia and basilar invagination is well known. Chamberlain, in his initial study referred to both these entities as being synonymous. ${ }^{[13]}$ 
Subsequently, various authors have questioned the clinical significance of platybasia and have considered it to be of anthropological significance only. The superior position of the odontoid process was associated with a more horizontal angulation and shortening of the clivus. ${ }^{[17]}$ Klaus also identified two groups of basilar invagination on the basis of the clival line of Wackenheim. ${ }^{[15,18]}$ He noted that in basilar invagination associated with platybasia, the tip of the odontoid process almost never reaches the Wackenheim clival line, while in a steeply shelving or normal clivus, the line from the dens often reaches or even over-shadows it. Platybasia was seen in both the groups but was relatively less in number and severity in Group A. From the study of Group B patients, it appears that platybasia was as important as invagination of the odontoid process in causing the anterior concavity of the brainstem and in reducing the volume of the posterior fossa. MarinPadilla $^{[19]}$ concluded from their study that the Chiarilike deformities reflect the effects of clival and occipital molding, which act mainly anteriorly. Platybasia did not directly result in any neurological symptoms, but it participated with basilar invagination in critically reducing the posterior cranial fossa volume. In our recent study,,$^{[1]}$ we demonstrated reversal of platybasia in Group A patients following the craniovertebral realignment surgery that involved distraction of facets of atlas and axis.

\section{Posterior cranial fossa volume}

The Klaus' height index ${ }^{[18]}$ measured on the MRI was seen to be much more accurate than the conventional measurements based on plain X-rays. The tentorium could be clearly identified on MRI and the distance of the tip of the odontoid from the line of the tentorium indicated the height of the posterior cranial fossa. On the basis of Klaus' index, the posterior fossa height was found to be markedly reduced in Group B patients while it was only moderately affected in Group A patients.

\section{Omega angle}

Although not frequently used, the Omega angle or the angulation of the odontoid process from the vertical as described by Klaus was found to be a useful guide. ${ }^{[18]} \mathrm{We}$ described a modified Omega angle as the measurement of the angle from the vertical was affected by the flexion and extension of the neck..$^{[1]]} \mathrm{A}$ line was drawn traversing through the centre of the base of the axis parallel to the line of the hard palate. The line of the hard palate was unaffected by the relative movement of the head and the cervical spine during the movement of the neck in these 'fixed' craniovertebral anomalies [Figure 4]. Facial hypoplasia or hard palate abnormality was not seen in any case in this series and did not affect the measurements. The Omega angle depicted the direction of displacement of the odontoid process. The Omega angle was severely reduced in Group A patients while it was much larger in Group B patients. The reduction

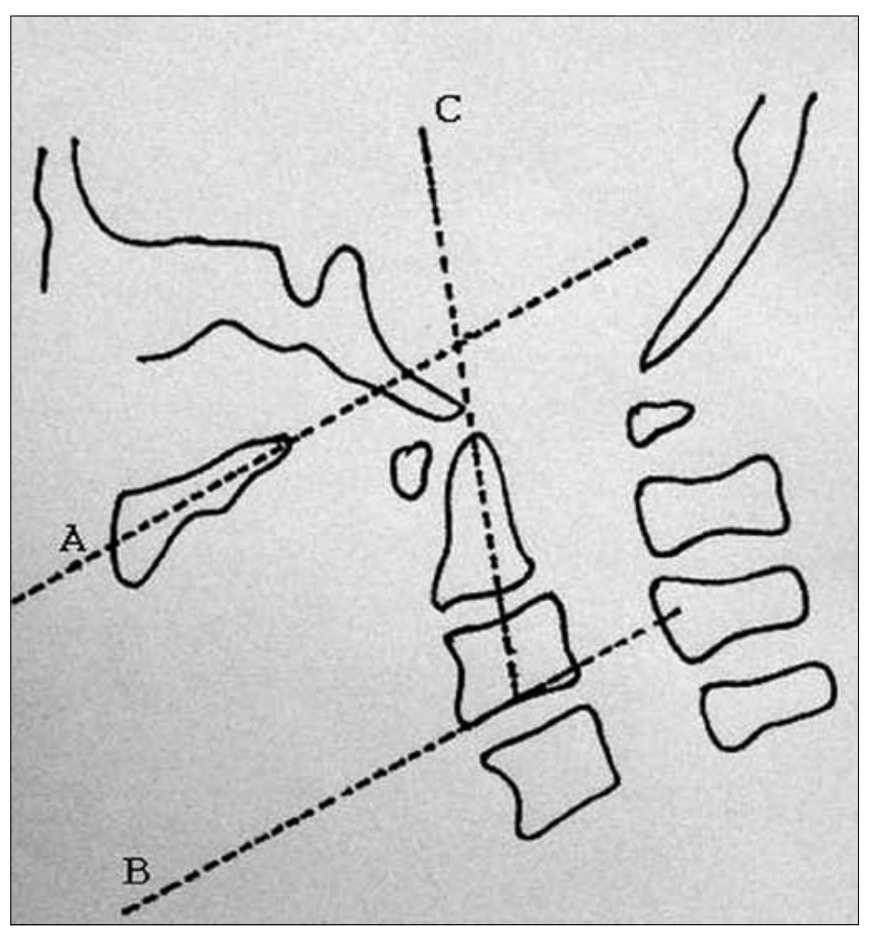

Figure 4: Line drawing showing parameters for measurement of modified omega angle to assess cervical lordosis. Line $A$ is drawn along the hard palate. Line $B$ is parallel to Line $A$ and passes through the centre of the base of $C 3$ vertebral body. Line $C$ extends from the center of the base of $\mathrm{C} 3$ along the tip of the odontoid process. The angle between Line B and Line $C$ is the modified omega angle

in the Omega angle in Group A patients depicted that the odontoid process had tilted towards the horizontal and was posteriorly angulated, while it was near vertical and superiorly migrated in Group B patients.

\section{Brainstem girth}

The effective brainstem girth measured on MRI was a useful additional parameter ${ }^{[11]}$ Whilst the brainstem girth was markedly reduced in Group A patients, the girth was only marginally affected or unaffected in Group B patients indicating thereby that there was no direct brainstem compression as a result of the odontoid process in the latter group.

The anterior concavity of the brainstem was smooth in curvature in Group B patients while it was acute in Group A patients, the angle being formed by the tip of the odontoid process. In Group A, the brainstem distortion was directly a result of indentation of the odontoid process. ${ }^{[11,20]}$

\section{Occipitalization of the atlas}

The association of occipitalization of the atlas with basilar invagination was noted first by Rakitansky [cited by Grawitz $\left.1880^{[8]}\right]$ and has since been referred to frequently. $[13,14,21,22]$ Many authors have regarded assimilation as a characteristic feature of basilar invagination. The assimilation of atlas can be partial or incomplete. 
Klippel-Feil bone anomaly refers to the triad of observations of extensive cervical vertebral fusions, low hairline, restrictions of neck movements and a short neck.

\section{Neck size}

Measurement of craniovertebral height can be done using a modification of Klaus's posterior fossa height index. ${ }^{[1,23,24]}$ The cervical height was measured from the tip of the odontoid process to the mid-point of the base of the C5-vertebral body [Figure 5]. The C-5 vertebral body base was used as the inferior limit for measuring the craniovertebral and cervical heights because in several available investigations the C6 and C7 vertebrae were not clearly delineated.

On direct physical measurement, neck length was observed to increase in the majority of patients. The parameter of measurement of neck length from inion to the tip of the $\mathrm{C} 7$ spinous process can be useful. ${ }^{[1,23]}$

\section{Clinical Features}

Majority of patients (58\%) with Group A basilar invagination had a history of minor to major head injury prior to the onset of the symptoms. The pyramidal symptoms formed a dominant component. Kinesthetic sensations were affected in $55 \%$ of patients. Spinothalamic dysfunction was less frequent (36\%). Neck pain was a major presenting symptom in $77 \%$ of patients. Torticollis was present in $41 \%$ of patients. ${ }^{[12]}$ The analysis of radiological and clinical features suggests that the symptoms and signs were a result of brainstem

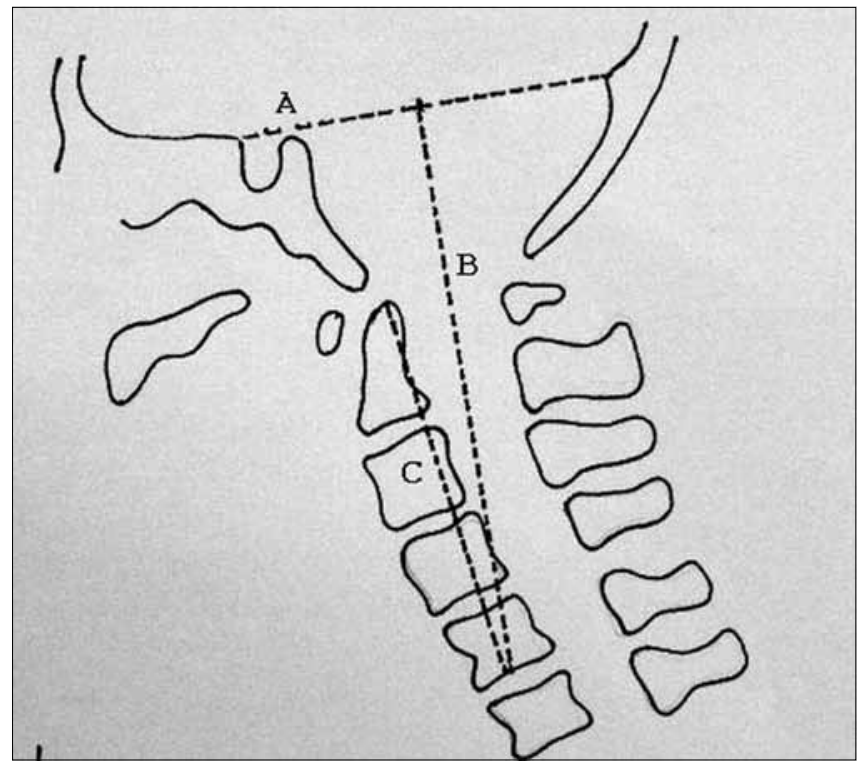

Figure 5: Line drawing showing the measurements of craniovertebral and cervical heights. Craniovertebral height: Line ' $A$ ' is drawn from the tuberculum sellae to the torcula. The distance from the midpoint of this line to the midpoint of the base of C5 vertebra (as shown by Line B) measures the craniovertebral height compression by the odontoid process.

The presentation was relatively acute in Group A patients while it was longstanding and slowly progressive in Group B patients In Group B patients, the onset of symptoms and their evolution were insidious. Thus, a careful inquiry was needed to pinpoint the timing of appearance of the initial symptoms. In the majority of patients, the time of onset was already forgotten. This made it difficult to establish with certainty the age at which the complaints began.

\section{Precipitating factors}

Trauma of varying severity was a noteworthy precipitating factor in Group A patients. ${ }^{[2,25]}$ Trauma seldom plays any major role in precipitating the symptoms in Group $B$ patients. The fact that trauma influenced the acute development of symptoms pointed towards an element of instability of the craniovertebral region in Group A patients. Infections probably precipitated the events in a few patients in Group A. Although long-term carrying of loads on the head as a precipitating factor has been recorded in some of the previous studies from India, ${ }^{[24]}$ it was not seen to be of any significance in our series.

\section{Associated clinical features}

Mere inspection of the patients with basilar invagination was of diagnostic value in the majority of patients in both the groups. However, short neck and torticollis were more frequently encountered in patients with Group A basilar invagination. The symptoms and signs in Group B basilar invagination appeared to be directly related to the 'crowding' of neural structures at the foramen magnum. Although the dimensions of the foramen magnum were large and sometimes larger than even in a normal state, the volume of its contents and probably the 'pulsatile' compression of the structures at the foramen magnum resulted in neurological symptoms. ${ }^{[26]}$ The markedly reduced girth of the brainstem in Group A patients clearly showed that direct compression of the brainstem by the odontoid process caused the neurological symptoms. Central cord symptoms and related signs were noted in patients associated with syringomyelia.

\section{Surgical Management}

We had recently studied the treatment of Group A basilar invagination, and discussed the feasibility of manipulation and distraction of the facets of atlas and axis and attempt towards reduction of the basilar invagination and fixation of the atlantoaxial joint. ${ }^{[10,12,27,28]}$ Our current experience with the technique of over 200 patients, has convinced us that distraction and direct lateral mass fixation of the atlantoaxial joint is the ideal treatment in patients with Group A basilar invagination 
and transoral surgery can be entirely avoided. The technique resulted in realignment of facets into the horizontal position and in realignment of the entire craniovertebral junction.

\section{Craniovertebral realignment for group A basilar invagination}

The standard and most accepted form of treatment of Group A basilar invagination is a transoral decompression. ${ }^{[11,12,20]}$ The majority of the authors recommend a posterior occipitocervical fixation following the anterior decompression.

Transoral odontoidectomy and resection of the superior half or third of the $\mathrm{C} 2$ body was a gratifying surgical procedure in Group A patients. ${ }^{[11]}$ Following this surgery, there was a clinical recovery in all the patients in this group. However, the long-term clinical outcome following the twin operation of transoral decompression followed by posterior stabilization was seen to be inferior to the clinical outcome following our current operation that involves craniovertebral realignment without any bone, dural or neural decompression. In Group A patients, the odontoid process was low-lying although posteriorly angulated. Surgery was helped by cervical traction as it reduced the posterior angulation and helped pulling the odontoid process inferiorly. The analysis of the pathology, the surgical experience and results suggest that anterior transoral decompressive surgery is relevant in Group A patients; although in our current evaluation we recommend craniovertebral realignment in these patients.

We had earlier attempted to reduce basilar invagination

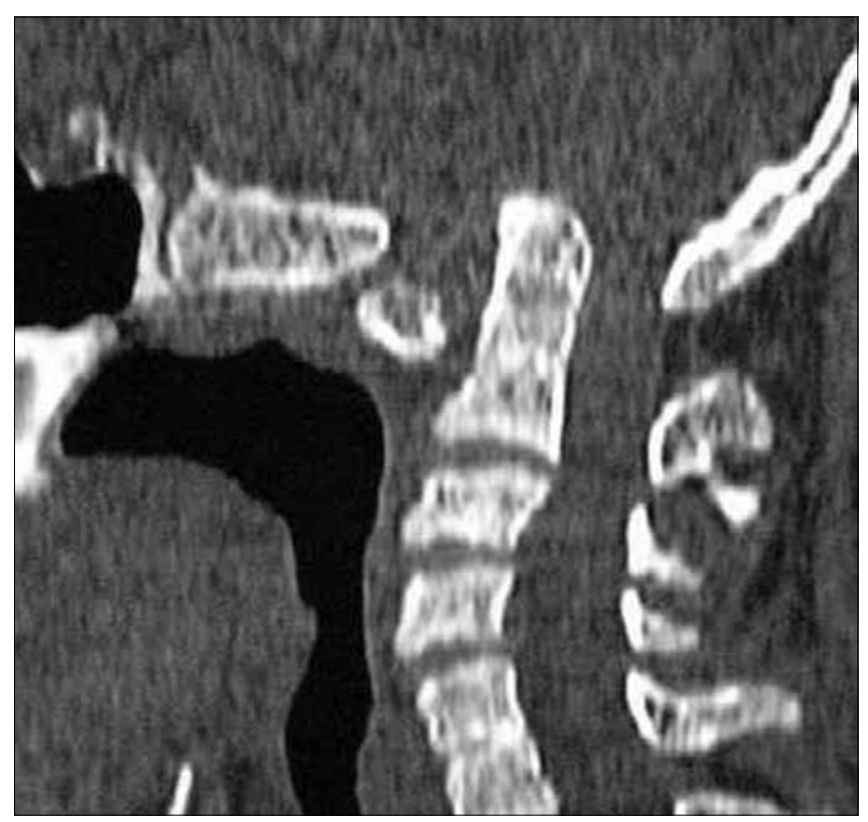

Figure 6a: CT scan showing Group A basilar invagination by performing occipitocervical fixation following institution of cervical traction. ${ }^{[11,20]}$ However, all the four patients treated in this manner subsequently needed transoral decompression as the reduction of the basilar invagination and of atlantoaxial dislocation could not be sustained by the implant. Our technique of craniovertebral realignment by wide removal of atlantoaxial joint capsule and articular cartilage by drilling and subsequent distraction of the joint by manual manipulation provided a unique opportunity to obtain reduction of the basilar invagination and of atlantoaxial dislocation.

\section{Surgical experience and technique of craniovertebral realignment}

All patients with Group A basilar invagination underwent joint manipulation surgery [Figures 6, 7]. No patient underwent a transoral decompression as a first-stage operation. The basic surgical steps of the joint manipulation surgery are the same as discussed in our papers on lateral mass plate and screw fixation of the atlantoaxial joint. The exposure of the atlantoaxial joint in patients with basilar invagination is significantly more difficult and technically challenging when compared to a normally aligned atlantoaxial joint encountered during the treatment of post-traumatic instability. The joint is significantly rostral in location and the microscope needs to be appropriately angled. Due to bony abnormalities of the region and frequently encountered rotation, the orientation can easily be lost. Cervical traction is given prior to induction of anesthesia and the weights are progressively increased to approximately one-fifth of the total body weight. The patient is placed prone with the head end of the table elevated to about 35 degrees.

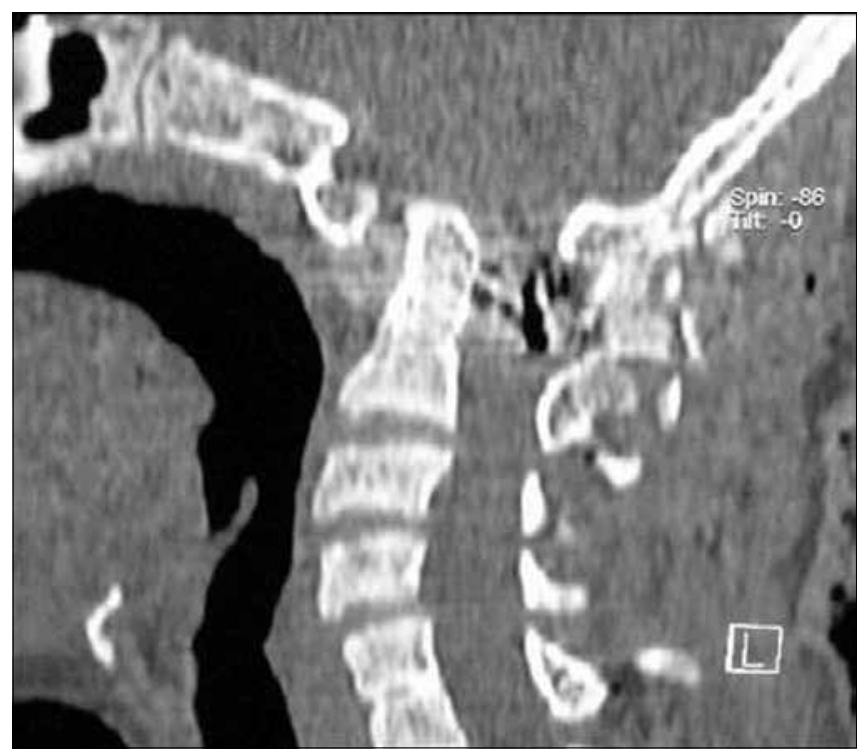

Figure 6b: Postoperative CT scan showing reduction of basilar invagination and fixation. No bone decompression has been done. Note the changes in craniovertebral and cervical alignments following surgery 


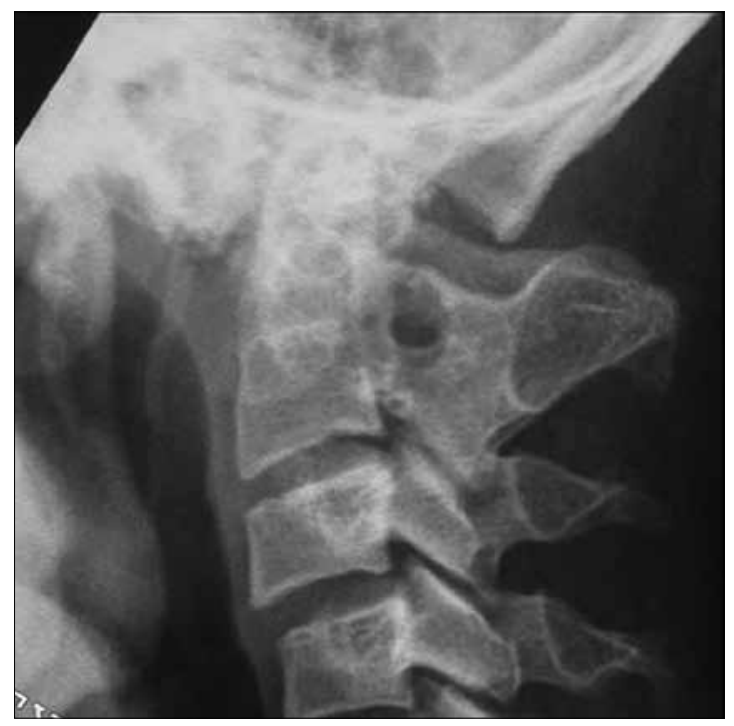

Figure 7a: Lateral X-ray of the craniocervical junction showing assimilation of the atlas, C2-3 fusion and basilar invagination

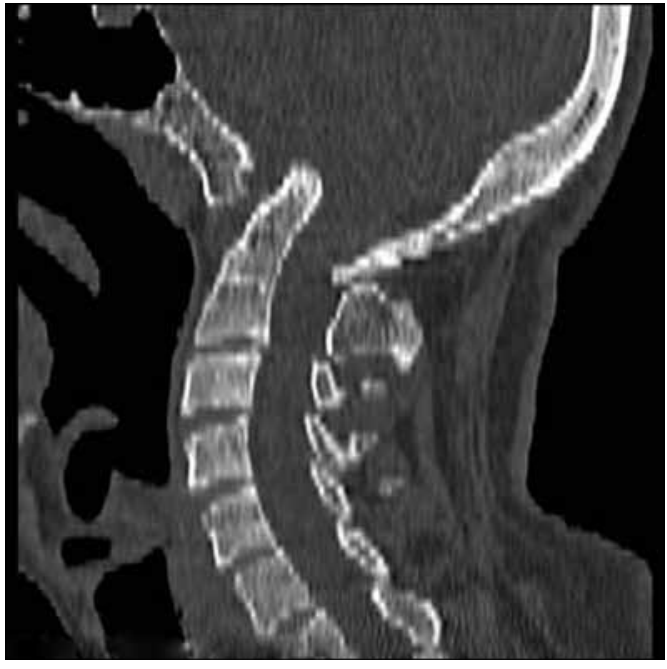

Figure 7c: CT scan showing Group A basilar invagination, assimilation of atlas and $\mathrm{C2}-3$ fusion

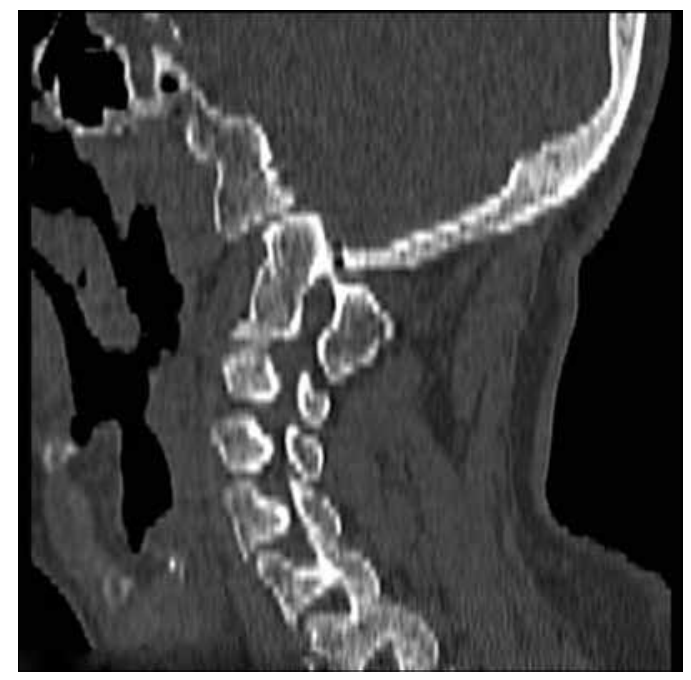

Figure 7e: Preoperative CT scan showing listhesis of C1 facet over C2 facet

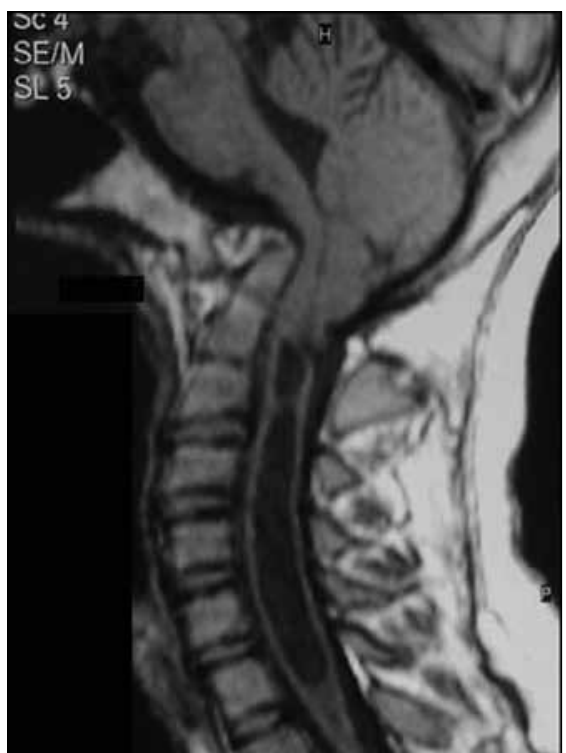

Figure 7b: T1-weighted MRI showing Group A basilar invagination, Chiari malformation and syringomyelia

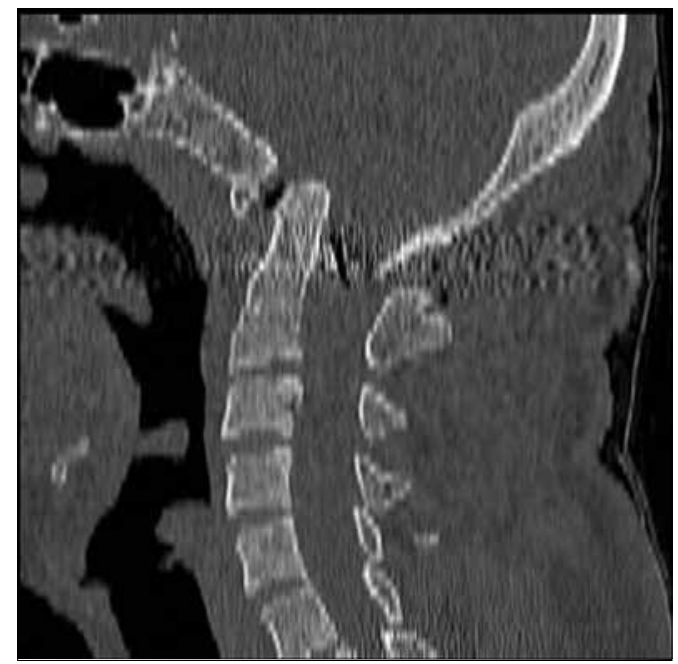

Figure 7d: Postoperative CT scan showing reduction of the basilar invagination and fixation

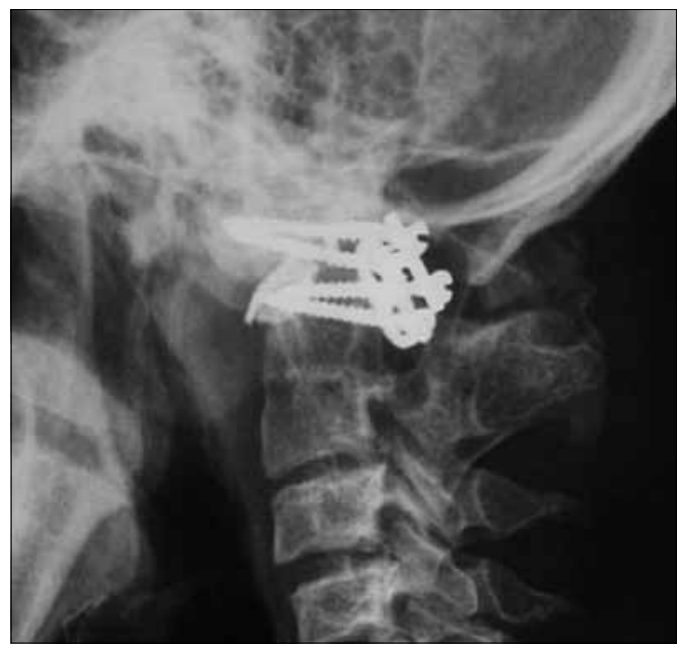

Figure 7f: Postoperative scan showing realignment of the atlantoaxial facets and fixation by plate and screws 


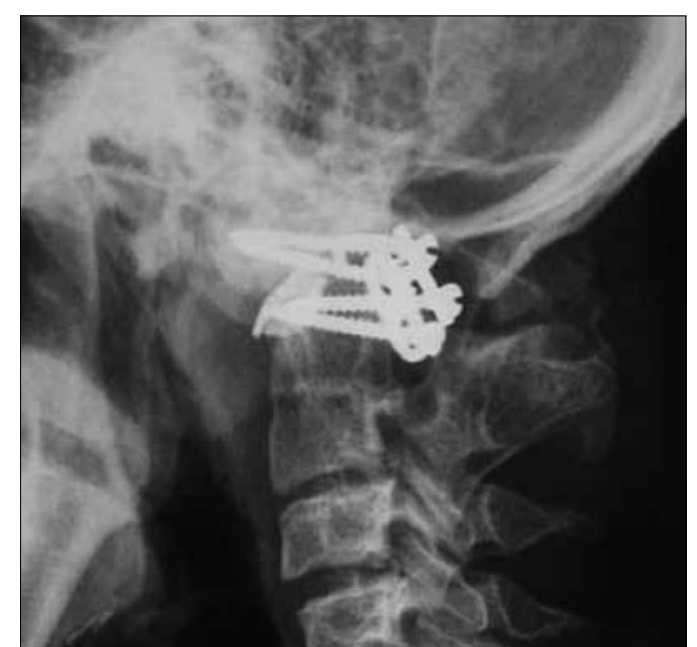

Figure 7g: Postoperative X-ray showing fixation with plate and screws. Note the presence of intra-articular spacers

Use of neuro-navigation assistance facilitated the dissection and added safety to screw implantation. The atlantoaxial facet joints are widely exposed on both sides after sectioning of the large $\mathrm{C} 2$ ganglion. The exposure of the facet of the atlas was significantly difficult as in a number of patients there was an assimilation of the atlas resulting in rostrally located C1 facet. The joint capsule is excised and the articular cartilage is widely removed using microdrill. The joint on both sides are distracted using an osteotome. The flat edge of the osteotome is introduced into the joint and it is then turned vertical to effect distraction. The status of the dislocation and of basilar invagination is evaluated by intraoperative radiographic control. Corticocancellous bone graft harvested from the iliac crest is stuffed into the joint in small pieces. Specially designed Titanium spacer or hydroxyappatite blocks are used in selected patients as strut graft and stuffed into the joints to provide additional distraction and stability. Maintenance of the joint in a distracted and reduced position with the help of bone graft with or without the assistance of hydroxyappatite or metal spacers and subsequent fixation of the joint with the help of interarticular screws and a metal plate provided a biomechanically firm fixation and sustained distraction. Holes in the titanium metal spacer provided space for bone fusion. The fixation was seen to be strong enough to sustain the vertical, transverse and rotatory strains of the most mobile region of the spine. Lateral mass plate and screw fixation of the region is subsequently carried out by the technique described by us earlier. ${ }^{[29,30]} \mathrm{A}$ two-holed stainless steel plate is used measuring $15-20 \mathrm{~mm}$ in length. The screws are 2.4 to $2.6 \mathrm{~mm}$ in diameter and measure $16-22 \mathrm{~mm}$ in length. Screws are passed bilaterally through the holes in the plate into the lateral mass of atlas and axis. In patients where due to anatomical or surgical technical limitation lateral mass plating cannot be completed, a
C1-C2 transarticular screw fixation method described by Mager ${ }^{[31]}$ or an occipitoaxial fixation ${ }^{[20,29,30]}$ can be done. The point of entry and the direction of screw for the transarticular fixation are altered to suit the complex local anatomy in these patients and are done under direct vision. Additional bone graft is placed between the posterior elements of $\mathrm{C} 1$ and $\mathrm{C} 2$ after decorticating the host bone area with a burr. Postoperatively the traction is discontinued and the patient is placed in a four-post hard cervical collar for three months and all his physical activities involving the neck are restrained during the period.

\section{Results of surgery}

The clinical neurological improvement varies but in most patients is remarkable and satisfying. All our patients had a sustained neurological improvement of varying degrees suggesting the effectiveness of the operation. Following surgery, the alignment of the odontoid process and the clivus and the entire craniovertebral junction improved towards normalcy. The tip of the odontoid process receded in relationship to Wackenheim's clival line, Chamberlain's line and McRae's line suggesting reduction in the basilar invagination. The posterior tilt of the odontoid process, as evaluated by modified omega angle, was reduced after the surgery. ${ }^{[11,18]} \mathrm{We}$ could obtain varying degrees of reduction of the basilar invagination and atlantoaxial dislocation. The extent of distraction of the joint and the subsequent reduction in the basilar invagination was more significant in younger than in older patients. In addition to the odontoid process changing its inclination, the angulation of the clivus also returned towards normalcy, suggesting that the entire craniovertebral junction was realigned by the procedure. The extent of neurological improvement observed by us after using the technique described appeared to be far more satisfactory and sustained when compared to the improvement obtained after a transoral surgery and the subsequent occipitocervical fixation. Despite the complex and deformed nature of the anomalies encountered in the series, there were no postoperative vascular, neurological or infective complications. In three patients, the reduction of the basilar invagination was not entirely satisfactory and a delayed transoral surgery was performed to decompress the region. No patient needed a re-exploration for failure of fixation of the implant. Immediate postoperative and follow-up radiographs confirmed fixation and fusion and reduction of the basilar invagination. Torticollis improved significantly following surgery in all patients. No patient complained of numbness in the suboccipital region, but on a leading question agreed to have a patch of suboccipital numbness. 


\section{Craniovertebral realignment for group A basilar invagination associated with syringomyelia}

We had classified syringomyelia and had suggested a specific treatment protocol on the basis of the possible pathogenetic factors. ${ }^{[32]}$ In this study we had suggested that syringomyelia is a tertiary response to primary craniovertebral anomaly in the form of basilar invagination which leads to secondary Chiari 1 malformation as a result of reduction in the posterior cranial fossa volume. Accordingly, a posterior fossa bony decompression was considered optimum in the treatment of this subgroup of patients.

We have identified patients of syringomyelia where there are associated bony abnormalities of the craniovertebral region that include 'fixed' atlantoaxial dislocation or those having Group A basilar invagination. This select group of patients is treated by attempts towards reduction of the atlantoaxial dislocation and of basilar invagination and by direct lateral mass plate and screw atlantoaxial fixation by techniques described by us ${ }^{[27]}$ No bony or dural decompression or neural manipulation of any kind is done in these patients.

The majority of the patients with Chiari malformationrelated syringomyelia without any bony anomaly of the craniovertebral region have hyporeflexia of the upper extremities and spastic lower extremities. Presence of spastic quadriparesis in all our patients suggests that the symptoms were related to the compression of the brainstem from invaginated dens rather than due to syringomyelia. It was observed that the patients were relatively young, neck pain formed a part of the symptom complex, and motor symptoms and ataxia were far more prominent symptoms in patients having the complex of malformation that included Group A basilar invagination, Chiari 1 malformation and syringomyelia than in patients with a similar complex but without craniovertebral region bony anomalies. It appears that when the angulation of the facets is not as acute or is only marginally affected, the progress of basilar invagination is slow and over several years, providing an opportunity for the syrinx to develop relentlessly.

It was observed that in patients of syringomyelia where there was 'fixed' atlantoaxial dislocation with or without the association of Group A basilar invagination and Chiari malformation, an attempt could be made to realign the bones in the craniovertebral junction. ${ }^{[12]}$ As observed by us earlier, it appears that the atlantoaxial joint in such patients is in an abnormal position as a result of congenital abnormality of the bones, and progressive worsening of the dislocation is probably secondary to increasing 'slippage' of the atlas over the axis. The fact that there was a remarkable clinical improvement following the reduction of the atlantoaxial dislocation and of basilar invagination, it appears that the complex of atlantoaxial dislocation, basilar invagination and syringomyelia are probably secondary to the primary craniovertebral instability. The Group A basilar invagination in patients with associated syringomyelia was less severe and symptoms were longstanding as compared to patients in whom there was no syringomyelia. The conduct of surgery and joint manipulation was relatively easier in these patients.

Following surgery, the alignment of the odontoid process and the clivus and the entire craniovertebral junction improved towards normalcy. We could obtain varying degrees of reduction of the basilar invagination and atlantoaxial dislocation. The atlantoaxial alignments changed towards normalcy and the tip of the odontoid process receded in relationship to Wackenheim's clival line and Chamberlain's line suggesting reduction in the basilar invagination and of atlantoaxial dislocation. The posterior tilt of the odontoid process, as evaluated by modified omega angle, was reduced after the surgery. ${ }^{[11,12]}$ All patients had a sustained neurological improvement of varying degrees suggesting the effectiveness of the operation. Stainless steel plates, non-locking variety of screws and custom-made spacers were used due to the higher costs of branded material. Due to the type of metal used in the procedure, the effect on syringomyelia not be confirmed.

\section{Reversibility of musculoskeletal changes following surgery}

We had recently analyzed the possibility of reversal of longstanding musculoskeletal changes in patients with Group A basilar invagination after surgical decompression and stabilization. ${ }^{[1]}$ The implications of such an analysis in understanding the pathogenesis of a number of features that are characteristically associated with basilar invagination were evaluated. One hundred and seventy selected patients with basilar invagination who underwent atlantoaxial joint distraction-fixation surgery between 1999 and April 2008 were evaluated in that study. In this series, prior to surgery there were several physical changes such as reduced neck length, torticollis, exaggerated lordosis of the cervical spine, and reduced craniospinal angulation. Other findings included reduced disc-space height, significant posterior cervical osteophytes formation, assimilation of atlas $(72 \%)$, single level $(29 \%)$ or multiple-level (3\%) cervical fusions, and an increase in spinal subarachnoid space both above and below the level of maximum neural compression at the tip of the odontoid process. After surgical decompression of the region, there was remarkable recovery in craniospinal alignment, and an increase in neck length (maximum $42 \mathrm{~mm}$ ) was obvious on physical and radiological examination in $85 \%$ of patients. The disc-space height increased and there 
was a reversal of altered cervical lordosis, craniospinal angulation (maximum up to 36 degrees), and torticollis. From our study we concluded that a number of physical spinal changes characteristically associated with basilar invagination such as a short neck, exaggerated neck lordosis, torticollis, cervical spondylotic changes and fusions are potentially reversible after decompression and stabilization of the craniovertebral junction.

Many authors have opined that congenital and developmental musculoskeletal abnormalities of the craniocervical junction complex can cause varying degrees of neural compression. Based on our analysis, it appears that neural compression at the craniovertebral junction is primary and the majority of physical and osseous abnormalities are probably secondary in nature. A variety of changes that probably occur in the bones and soft tissues appear to be directly related to the natural adjustments that operate to minimize the compression of the cord by the indentation of the odontoid process and the instability of the region. The restriction of neck movements, reductions of neck length, and alterations in the craniospinal angulation probably lead to the presence of large subarachnoid spaces in relationship to the cervical cord and to the brainstem. All these natural responses probably allow the cord a relatively stretchfree traversal over the indenting odontoid process. Reduction of the disc spaces, osteophyte formation, incomplete and complete cervical fusions, and alterations in the craniospinal and cervical angulations appear to be directly related to the reduction in neck length. The reduction in the disc-space height and fusions are more prominently seen in the upper cervical vertebrae. It appears that cervical fusions and assimilation of the atlas may be related to longstanding and progressive reduction in the disc-space height.

\section{Foramen magnum decompression for group B patients}

It appears from the analysis of the results in our series, that patients in Group B benefited by foramen magnum bony decompression. The procedure resulted in amelioration of symptoms and at least an arrest in the progression of the disability. None of the patients in this group had a delayed worsening in the neurological condition following a foramen magnum decompression. Driesen reported that during operations for craniovertebral anomalies, he often had to remove noticeably thickened pieces of bone from the posterior edge of the foramen magnum. ${ }^{[25]}$ In our patients, the suboccipital bone and posterior rim of the foramen magnum and the dura overlying the herniated cerebellar tissue were thin in a significant number of patients. This probably was related to the chronic pressure changes secondary to the reduced posterior cranial fossa volume. The bulbous lipping of the posterior rim of the foramen magnum represents the rudiments of the posterior arch of the atlas assimilated into the occipital bone. ${ }^{[4]}$ Various authors have recommended that to achieve maximal decompression, it is necessary to open the dura mater and to cut all constrictive dural and arachnoidal bands. Some authors have recommended leaving the dura open while others have recommended the placement of a graft. Current papers do not recommend resection of the herniating tonsils ${ }^{[33]}$ or even sectioning of adhesions around it. The fact that dural opening was not necessary whilst performing posterior fossa or foramen magnum decompression was first described by us in 1997. ${ }^{[1]}$ This was based on the understanding that the dura is an expansile structure and can never be a compressive factor ${ }^{[27,34]}$ Opening of the dura is not only unnecessary but also subjects the patient to an increased risk of cerebrospinal fluid fistula. It turns an otherwise simple surgery into a relatively complex and dangerous surgical maneuver. The treatment of syrinx in the presence of Chiari malformation is also controversial. Logue reported 75 patients treated with craniovertebral decompressions for Chiari malformations and syringomyelia. ${ }^{[35]}$ The patients were divided into two groups: one treated with decompression only, leaving the arachnoid intact, and the other treated with Gardner's procedure of opening the fourth ventricle and plugging the upper cervical canal. They concluded that muscle plugging did not seem to change the results. Levy et al., also concluded on the same lines. ${ }^{[36]}$ Logue noticed that there was no significant need for performing a syringosubarachnoid shunt following craniovertebral decompression. ${ }^{[35]}$ Various subsequent studies have questioned the need for a syrinx drainage surgery following foramen magnum decompression. Di Lorenzo et al., concluded from their study that 'conservative' craniocervical decompression should be considered the first option in the treatment of syringomyelia-Chiari 1 complex. ${ }^{[37]}$ Our experience suggests that only bony decompression of the foramen magnum is sufficient even in patients with syringomyelia.

Chiari 1 malformation and secondary syringomyelia frequently are not associated with basilar invagination. The exact cause of Chiari malformation in such patients is only speculative. However, the treatment even in such patients is only foramen magnum bone decompression.

The treatment of basilar invagination must be based on the understanding of its pathogenesis. As complications related to an inappropriate treatment can be devastating in nature, exact anatomical and biomechanical evaluation and precise surgical treatment is mandatory in these patients.

\section{References}

1. Goel A, Shah A. Reversal of longstanding musculoskeletal changes in basilar invagination after surgical decompression and stabilization. J Neurosurg Spine 2009;10:220-7. 
2. David KM, Thorogood PV, Stevens JM, Crockard HA. The dysmorphic cervical spine in Klippel-Feil syndrome: interpretations from developmental biology. Neurosurg Focus 1999;6:E1.

3. Gunderson CH, Greenspan RH, Glaser GH, Lubs HA. The Klippel-Feil syndrome: genetic and clinical reevaluation of cervical fusion. Medicine 1967;46:491-512.

4. Menezes AH. Primary craniovertebral anomalies and hindbrain herniation syndrome (Chiari I): data base analysis. Pediatr Neurosurg $1995 ; 23: 260-9$.

5. Pradhan M, Behari S, Kalra SK, Ojha P, Agarwal S, Jain VK. Association of methylenetetrahydrofolate reductase genetic polymorphisma with atlantoaxial dislocations. J Neurosurg Spine 2007;7:623-30.

6. Virchow R. Beitrage zur physischen Anthropologie der Deutschen, mit besonderer Berucksichtigung der Friesen. Berlin: Abhandlungen de Koniglichen Akademie der Wissenschaften, 1876.

7. Von Torklus D, Gehle W. The Upper Cervical Spine: Regional Anatomy, Pathology, and Traumatology. A Systematic Radiological Atlas and Textbook. New York: Grune and Stratton; 1972. p. 1-98.

8. Grawitz P. Beitrag zur Lehre von der basilaren Impression des Schadels. Arch Path Anat Physiol 1880;80:449.

9. Kothari M, Goel A. Transatlantic odonto-occipital listhesis: the so-called basilar invagination. Neurol India 2007;55:6-7.

10. Goel A. Progressive basilar invagination after transoral odontoidectomy: treatment by facet distraction and craniovertebral realignment. Spine 2005;30:E551-5.

11. Goel A, Bhatjiwale M, Desai K. Basilar invagination: a study based on 190 surgically treated cases. J Neurosurg 1998;88:962-8,

12. Goel A. Treatment of basilar invagination by atlantoaxial joint distraction and direct lateral mass fixation. J Neurosurg Spine 2004;1:281-6.

13. Chamberlain WE. Basilar impression (platybasia). A bizarre developmental anomaly of the occipital bone and upper cervical spine with striking and misleading neurologic manifestations. Yale J Biol Med 1939;11:487-96.

14. MeRae DL. Bony abnormalities in the region of foramen magnum: correlation of anatomic and neurologic findings. Acta Radiol 1953;40:335-54.

15. Thiebaut F, Wackenheim A, Vrousos C. New median sagittal pneumostratigraphical findings concering the posterior fossa. J Radiol Electrol 1961;42:1-7.

16. Goel A, Shah A, Rajan S. Vertical mobile and reducible atlantoaxial dislocation. J Neurosurg Spine 2009; July (in press).

17. Malis LI, Cohen I, Gross SW. Arnold-Chiari malformation. Arch Surg 1951;63:783-98.

18. Klaus E. Rontgendiagnostik der platybasic und basilaren Impression. Fortscher Rontgenstr 1957;86:460-9.

19. Marin-Padilla M. Cephalic axial skeletal-neural dysraphic disorders: embryology and pathololgy. Can J Neurol Sci 1991;18:153-69.

20. Goel A, Achawal S. Surgical treatment for Arnold Chiari malformation associated with atlantoaxial dislocation. Br J Neurosurg 1995;9:67-72.

21. Spillane JD, Pallis CH, Jones AM. Developmental abnormalities in the region of the foramen magnum. Brain 1957;80:11-47.

22. Virchow R. Untersuchungen fiber die Entwicklung des Schadelgrundes. Berlin: Reimer; 1857.

23. Mahajan PV, Bharucha BA. Evaluation of short neck: new neck length percentiles and linear correlations with height and sitting height. Indian Pediatr 1994;31:1193-203

24. Bharucha EP, Dastur HM. Craniovertebral anomalies: A report on 40 cases. Brain 1964:87:469-80.

25. Driesen W. Findings at operation in the central nervous system in basilar impressions and related abnormalities of the atlanto-oceipital region. Acta Neurochir 1960;9:9-68 (Ger).

26. Williams B. A critical appraisal of posterior fossa surgery for communicating syringomyelia. Brain 1978;101:223-50.

27. Goel A, Sharma P. Craniovertebral junction realignment for the treatment of basilar invagination with syringomyelia: preliminary report of 12 cases. Neurol Med Chir (Tokyo) 2005;45:512-8.

28. Goel A, Kulkarni AG, Sharma P. Reduction of fixed atlantoaxial dislocation in 24 cases: technical note. J Neurosurg Spine 2005;2:505-9.

29. Goel A, Desai K, Muzumdar D. Atlantoaxial fixation using plate and screw method: A report of 160 treated patients. Neurosurgery 2002;51:1351-7.

30. Goel A, Laheri VK. Plate and screw fixation for atlanto-axial dislocation: (Technical report). Acta Neurochir (Wien) 1994;129:47-53.

31. Grob D, Magerl F. Operative stabilisierung bei fraketuren von C1 und C2. Orthopade 1987;16:46-54.

32. Goel A, Desai KI. Surgery for syringomyelia: An analysis based on 163 surgical cases. Acta Neurochir (Wien) 2000;142:293-302.

33. Fischer EG. Posterior fossa decompression for Chiari 1 deformity, including resection of the cerebellar tonsils. Childs Nerv Syst $1995 ; 11: 625-9$

34. Kothari M, Goel A. Maternalizing the meninges: A pregnant Arabic legacy. Neurol India 2006;54:345-6.

35. Logue V, Edwards MR. Syringomyelia and its surgical treatment: an analysis of 75 patients. J Neurol Neurosurg Psychiatry 1981;44:273-84.

36. Levy WJ, Mason L, Hahn JF. Chiari malformation presenting in adults: a surgical experience in 127 cases. Neurosurgery 1983;12:377-90.

37. Di Lorenzo N, Fortuna A, Guidetti B. Craniovertebral junction malformations: Clinicoradiological findings, long-term results, and surgical indications in 63 cases. J Neurosurg 1982;56:603-8.

Accepted on 09-06-2009

Source of Support: Nil, Conflict of Interest: None declared. 